\title{
DIGLOSSIA EM TEMPOS DE MUDANÇA? O CASO DA INTERPOLAÇÃO EM DUARTE GALVÃO, PERO MAGALHÃES DE GANDAVO, FRANCISCO DE HOLANDA E DIOGO DO COUTO
}

\author{
Cristiane NAMIUTI-TEMPONI*
}

- RESUMO: De acordo com Castro (1991) e Cardeira (2005), o século XV e a primeira metade do XVI são um período de transição da língua medieval para a clássica, no qual coexistem formas próprias da etapa anterior com formas que já anunciam o português do período clássico. Inspirados nas reflexões de Castro (1991) e Cardeira (2005) e também na ideia de competição de gramáticas delineada por Kroch (1994), argumentamos que um período de transição deverá caracterizar-se pela instabilidade resultante da conjugação dos sinais de renovação que se cruzam com a permanência da gramática antiga. Apresentaremos, neste artigo, alguns indícios provenientes da sintaxe dos clíticos em textos de autores nascidos entre o século XV e XVI que podem corroborar a hipótese de instabilidade gramatical e competição de gramáticas nessa época.

- PALAVRAS-CHAVE: Sintaxe. Interpolação. Mudança sintática. Diacronia. Gramática gerativa.

\section{Introdução}

O trabalho que apresentaremos aqui se enquadra na perspectiva diacrônica da sintaxe gerativa que busca compreender de que forma os dados de língua refletem alterações no plano das gramáticas. Trazemos uma reflexão sobre como avaliar os dados deixados pela escrita e uma proposta de interpretação para os dados encontrados em quatro textos de autores nascidos entre 1435 e 1542, que compõem o Corpus histórico do português anotado Tycho Brahe. ${ }^{1}$ Tais autores nasceram em uma época de transição entre dois períodos gramaticais

* UESB - Universidade Estadual do Sudoeste da Bahia. Departamento de Estudos Linguísticos e Literários. Vitória da Conquista - BA - Brasil. 45083-900 - cristianenamiuti@gmail.com

1 CORPUS... (2007).

Textos do corpus Tycho Brahe em evidência neste trabalho:

- Duarte Galvão (1435-1517): Chronica do muito alto e muito esclarecido principe D. Affonso Henriques primeiro Rey de Portugal;

- Pero Magalhães de Gandavo ( 1502-??): História da prouincia Sãcta Cruz que vulgarme[n]te chamamos Brasil;

- Francisco de Holanda (1517-1584): Da Pintura Antiga;

- Diogo do Couto (1542-1606): Décadas. 
que antecederam as variantes atuais do português contemporâneo (português europeu e português brasileiro) - os períodos hoje tradicionalmente designados de Português Antigo e Português Clássico. Sobre essa época, escreve Paul Teyssier (2001, p.81-82):

Na leitura de um texto de fins do século XVI, a penosa impressão de arcaísmo dos textos antigos cede lugar a um agradável sentimento de modernidade. Se necessidade houvesse de fixar uma data ou um acontecimento para marcar esta mudança, uma ou outra coincidiriam com a publicação, em 1572, de Os lusíadas, de Luís de Camões. [...] Para chegar a essa fase, o português sofreu, do século XIV ao XVI, uma série de transformações que tiveram como efeito fixar a morfologia e a sintaxe de tal maneira que daí por diante pouco variarão.

Vários trabalhos têm argumentado que as mudanças nas línguas instanciamse, nos documentos históricos, como variação entre formas antigas e formas novas. ${ }^{2}$ Tipicamente, essa variação resulta no estabelecimento da nova forma na língua (KROCH, 1989).

No caso da língua portuguesa, dois aspectos da sintaxe dos clíticos pronominais se destacam pelas alterações de padrão na diacronia: (i) as ordens relativas clítico-verbo verbo-clítico - variação próclise e ênclise; e (ii) o fenômeno da interpolação.

A variação superficial verbo-clítico clítico-verbo em orações não dependentes com verbo em segunda posição (X-V) é atestada nos textos escritos entre 12001900. Mas a preponderância da ênclise ou da próclise em diferentes períodos aliada a outros aspectos da sintaxe (como o fenômeno do fronteamento e o estatuto do sujeito pré-verbal) sugerem diferentes estruturas subjacentes a essas ordenações e, consequentemente, diferentes etapas gramaticais (GALVES; NAMIUTI; PAIXÃO DE SOUSA, 2006): a ênclise predomina nos textos escritos entre 1200 e 1400 e entre 1750 e 1900, é categórica neste contexto, no Português Europeu Moderno (séculos XX e XXI); mas, no período que abrange o final do século XV, os séculos XVI, XVII e o início do XVIII, é a próclise que predomina nos textos escritos, com a possibilidade de interpolação da negação nos mesmos contextos sintáticos da variação verbo-clítico clítico-verbo. Seguem exemplos dessas estruturas em orações não dependentes introduzidas por sujeito (NAMIUTI, 2008):

(1) “[...] espírito é como vento, com o mesmo com que uns vão para cima, vão outros para baixo; eu acho-me bem em caminhos chãos, ainda que me seja preciso vadear serras e meter debaixo dos pés os montes". - Chagas, $1631{ }^{3}$

2 Podemos citar aqui Meillet (1928), Weinrich (1953), Labov (1965) entre outros.

3 Os dados exemplificados apresentam-se com o nome do autor e a data de seu nascimento. Tais dados foram extraídos do Corpus Tycho Brahe e fazem parte do banco de dados da tese de Namiuti (2008). 
(2) "Ele me disse que pasmava como lhe abastava o que tinha." - Sousa, 1554.

(3) “Dom Manoel de Lima o não quiz ouvir naquele negócio, dizendo-lhe, que era filho mais velho de seu pai, que se queria ir pera o Reino, e que quando lhe ElRei não desse de comer, que viveria com o que seu pai viveo." - Couto, 1548.

Neste artigo, focalizaremos o fenômeno da interpolação. Trata-se de uma construção característica dos textos mais antigos do português (bem como do romance ibérico em geral, Rivero (1993), Martins (1994), entre outros), na qual o clítico pronominal não se apresenta contíguo ao verbo. Tal construção está em variação com adjacência clítico-verbo nos contextos de próclise categórica (MARTINS, 1994; RIBEIRO, 1995; PARCERO, 1999; FIÉIS, 2001; NAMIUTI, 2008).

(4) "E não faltou quem murmurasse de António de Almeida, havendo que vinha peitado dos Castelhanos, porque trazia peças, e brincos, que lhe êles deram." - Couto, 1542.

É importante ressaltar que, conforme argumentamos em Namiuti $(2006,2008)$, existem dois fenômenos que são tradicionalmente considerados interpolação: (i) a interpolação de diversos constituintes que podem ocupar a posição préverbal, presente somente nos textos antigos (interpolação generalizada); e, (ii) a interpolação da negação que continua presente nos textos tardios e no português europeu moderno. ${ }^{4}$

De acordo com Martins (1994) a perda do fenômeno da interpolação generalizada em português se dá no século XVII, juntamente com a perda da possibilidade da próclise em orações raízes (X-V).

No entanto, o estudo que realizamos em vinte textos literários que compõem o Corpus do Português Histórico Tycho Brahe (doravante CTB) revela que o fenômeno da interpolação de elementos diferentes da negação é obsoleto nos textos dos autores quinhentistas e seiscentistas (NAMIUTI, 2008); a seção Estado da arte: o fenômeno da interpolação no corpus Tycho Brahe deste artigo traz um aparato geral do quadro apresentado por esse corpus.

Considero, portanto, os fatos relativos ao fenômeno da interpolação importantes para compreendermos a mudança gramatical que, segundo a proposta delineada em Namiuti (2008), remonta ao século XV.

A interpolação generalizada é robustamente atestada nos textos escritos entre 1200-1400 (MARTINS, 1994; FIÉIS, 2001) e marginal na maioria dos autores do CTB nascidos após 1500. No entanto, os textos representativos dos séculos XV e XVI revelam uma significativa variação entre as preferências de uso da construção.

4 Em Namiuti $(2006,2008)$ argumentamos fortemente sobre o estatuto diferenciado da interpolação da negação. 
Enquanto alguns persistem no uso dessa interpolação, como Duarte Galvão (1435-1517) e Francisco de Holanda (1517-1584), com 40\% e 44\% de interpolação generalizada cada um, outros, como Pero Magalhães Gandavo (1502-??), não atestam o fenômeno.

Neste presente artigo, apresentaremos uma descrição detalhada do fenômeno característico do português antigo nos textos dos autores nascidos nos séculos XV e XVI. E, sob a luz teórica da gramática gerativa e da proposta delineada por Kroch $(1989,2001)$, conferiremos e argumentaremos que o século XV pode ser considerado um período de mudança e instabilidade gramatical, no qual as formas antigas ainda aparecem robustamente no início do período, mas já com o surgimento de novas formas que indicariam o nascimento de uma nova gramática do português nesse século. Nossa visão tem consequências para as delimitações dos períodos gramaticais, uma vez que consideremos que é o surgimento de uma nova forma a pista que indica o surgimento de uma nova gramática e não o desaparecimento total da forma antiga nos textos escritos.

\section{Para modelar a variação: laço teórico}

Na perspectiva gerativista, a mudança gramatical é uma função da relação entre a capacidade inata e a experiência linguística vivenciada pelas sucessivas gerações de falantes. As diferenças sintáticas entre dois ou mais estágios de uma língua, assim como as diferenças entre as línguas, são analisadas no quadro da teoria gerativa em termos de fixação diferente de valores paramétricos. Desse modo, a mudança sintática é vista como mudança de parâmetro, e fortemente vinculada à aquisição.

Assim, ao levantar a hipótese de uma etapa gramatical, os estudos gerativistas buscam compreender a que padrão de marcação paramétrica corresponde um determinado conjunto de dados.

Reconhecendo a distância existente entre a produção escrita e a gramática, os estudos de mudança no quadro gerativista enfrentam alguns desafios metodológicos, uma vez que a gramática é um objeto teórico e os dados um objeto empírico a ser interpretado.

Assumimos o quadro delineado por Kroch (1989, 1994, 2001), que salienta que a variação nos textos não se deve confundir com a variação nas gramáticas, uma vez que a mudança gramatical na teoria gerativa envolve mudança paramétrica e está fortemente vinculada à aquisição da linguagem pela criança, que as mudanças nas línguas, instanciadas nos documentos históricos como variação gradual, devem, por necessidade teórica, refletir mudanças gramaticais que ocorreram individualmente. Portanto, Kroch $(1989,2001)$, adotando a postura 
gerativista, considera que a mudança real na fixação do parâmetro deve ser abrupta, ocorrer no vernáculo sem ser observada e somente a competição da gramática nova com a antiga, ou o uso escolarizado conservador, é acessível para ser estudada nos textos.

Nessa perspectiva, a variação entre formas antigas e novas na linha do tempo não pode ser conceituada como uma "oscilação" produzida por uma única gramática particular. Ao contrário, cada forma deverá corresponder a diferentes fixações de um parâmetro.

Dessa forma, apesar da mudança ocorrer instantaneamente no vernáculo, a substituição de uma forma por outra se dá gradualmente. A variação nos textos pode ser compreendida como fruto da convivência, no plano do uso, de formas geradas por diferentes gramáticas. É o que Kroch (1994) chama de "competição de gramáticas", processo no qual as formas antigas são gradualmente expulsas do uso pelas formas inovadoras.

Assim, a mudança sintática, uma vez implementada, produz uma lenta mudança no sentido das frequências de uso das formas nova e velha. As diferenças nas frequências podem refletir, segundo Kroch (1989, 2001), preferências estilísticas ou efeito de processamento psicolinguístico.

Com relação à motivação e à explicação para as mudanças sintáticas, Kroch $(1989,2001)$ propõe que, quando a evidência para a fixação de um dado parâmetro se torna fraca, alguns aprendizes não vão ser expostos a dados suficientes para fixar o parâmetro corretamente. O resultado será uma população mista na qual alguns falantes têm a fixação paramétrica antiga e outros, a nova. Nessa população mista, a próxima geração provavelmente será menos exposta aos dados necessários para fixar o parâmetro do jeito antigo. Dessa forma, a variação no uso que reflete diferentes fixações paramétricas é encontrada nos textos escritos.

Para modelar essa variação, Kroch (2001) também propõe ser necessário permitir a diglossia sintática como uma situação normal durante o período de mudança. E uma vez que uma comunidade se torna diglóssica com relação a uma dada fixação paramétrica, os falantes poderiam aprender ambos os parâmetros, e a escolha de qual critério de boa formação que deva ser aplicado na produção de uma dada instância de fala recairia no domínio da performance. As formas em competição em diglossia sintática representariam, segundo Kroch (2001), uma oposição entre um vernáculo inovador e uma língua conservadora. E, já que a primeira teria vantagem tanto psicolinguística quanto numérica, ela deverá vencer ao longo do tempo, até mesmo em textos escritos. Dessa maneira, a gradação encontrada nos textos não deve refletir qualquer mecanismo básico de mudança linguística, mas sim o bilinguismo psico e/ou sociolinguístico. 
No que concerne especificamente ao problema da identificação de etapas gramaticais ou à periodização, a contribuição central do conceito de Competição de Gramáticas é a ideia de que a emergência de uma nova gramática será identificada pelo surgimento de formas novas nos dados. (GALVES; NAMIUTI; PAIXÃO DE SOUSA, 2006).

\section{Estado da arte: o fenômeno da interpolação no corpus Tycho Brahe}

Os dados de interpolação de elementos diferentes da negação nos textos do CTB limitaram-se aos textos de autores nascidos até a primeira metade do século 17. Diogo do Couto (1542-1606), Frei Luís de Sousa (1556-1632), Francisco Rodrigues Lobo (1574-1621), Francisco Manuel de Melo (1608-1666) e António das Chagas (1631-1682) são os autores dos últimos textos que registraram a interpolação de elementos diferentes de não. Depois, temos um vasto período em que nada, a não ser a negação, é interpolado, o que está de acordo com outras pesquisas que observaram esse fenômeno (MARTINS, 1994; PARCERO, 1999; FIÉIS, 2001).

Constatamos que a interpolação de elementos diferentes da negação já não é preferencial no texto de Duarte Galvão (1435-1517) (40\%) e é obsoleta em Diogo do Couto (1542-1606) (15\%). E o mais surpreendente, o fenômeno não foi atestado no texto de Pero Magalhães de Gandavo (1502- ??) (0\%). Os textos tardios - de Luís de Sousa, Francisco Rodrigues Lobo, Francisco Manuel de Melo e António das Chagas apresentaram uma frequência abaixo de 2\% (mais exatamente $1 \%, 2 \%, 2 \%$ e $0,4 \%$ ) de interpolação de elementos diferentes da negação ao compararmos com os casos de adjacência 'clV' com potencialidade para a interpolação. Também seus contemporâneos não atestaram o fenômeno nos seus inúmeros casos de próclise, como podemos constatar na tabela 1 a seguir, referente à interpolação generalizada versus adjacência $\mathbf{c l}-\mathbf{V}$ nos contextos potenciais para a interpolação. 
Tabela 1 - Interpolação generalizada versus adjacência 'clV'

\begin{tabular}{|c|c|c|c|c|c|c|c|c|c|c|c|c|c|c|c|}
\hline \multirow[t]{2}{*}{ Autores } & G00 & G00 & $\mathrm{H} 00$ & $\mathrm{C} 00$ & S00 & L00 & V00 & V00 & M00 & $\mathrm{C} 00$ & B00 & B00 & $\mathrm{C} 00$ & B00 & $\mathrm{A} 00$ \\
\hline & 9 & 8 & 1 & 7 & 1 & 1 & 4 & 2 & 3 & 3 & 3 & 8 & 2 & 1 & 1 \\
\hline \multirow[t]{2}{*}{ Data de edição } & 151 & 157 & 154 & 161 & 161 & 161 & 169 & 169 & 166 & 168 & 172 & 173 & 172 & 174 & 175 \\
\hline & 7 & 6 & 8 & 6 & 9 & 9 & 7 & 7 & 4 & 7 & 8 & 5 & 1 & 6 & 2 \\
\hline \multirow{2}{*}{$\begin{array}{c}\text { Data de } \\
\text { nascimento }\end{array}$} & 143 & 150 & 151 & 154 & 155 & 157 & 160 & 160 & 160 & 163 & 164 & 165 & 165 & 167 & 170 \\
\hline & 5 & 2 & 7 & 2 & 6 & 4 & 8 & 8 & 8 & 1 & 4 & 1 & 8 & 5 & 5 \\
\hline \multirow[t]{3}{*}{ C-CL-X-(X)-V } & 73 & 0 & 76 & 37 & 3 & 7 & 0 & 0 & 9 & 2 & 0 & 0 & 0 & 0 & 0 \\
\hline & 0,4 & 0,0 & 0,4 & 0,1 & 0,0 & 0,0 & 0,0 & 0,0 & 0,02 & 0,00 & 0,0 & 0,0 & 0,0 & 0,0 & 0,0 \\
\hline & 0 & 0 & 4 & 5 & 2 & 0 & 0 & 0 & & 4 & 0 & 0 & 0 & 0 & 0 \\
\hline \multirow[t]{3}{*}{ C-X-(X)-CL-V } & 109 & 17 & 98 & 207 & 308 & 416 & 387 & 430 & 586 & 472 & 346 & 234 & 264 & 295 & 641 \\
\hline & 0,6 & 1,0 & 0,5 & 0,8 & 0,9 & 1,0 & 1,0 & 1,0 & 0,98 & 0,99 & 1,0 & 1,0 & 1,0 & 1,0 & 1,0 \\
\hline & 0 & 0 & 6 & 5 & 9 & 0 & 0 & 0 & & 6 & 0 & 0 & 0 & 0 & 0 \\
\hline $\begin{array}{c}\text { Total de C-CL-X- } \\
\text { (X)-V e C-X-(X)- } \\
\text { CL-V }\end{array}$ & 182 & 17 & 174 & 244 & 311 & 423 & 387 & 430 & 595 & 474 & 346 & 234 & 264 & 295 & 641 \\
\hline
\end{tabular}

Fonte: Corpus (2007).

Apesar de encontrarmos alguns casos de interpolação nos textos de autores nascidos no início do século XVII, acreditamos que a mudança que veda a possibilidade de gerar a interpolação generalizada deve ser bastante anterior, uma vez que vários dos autores contemporâneos àqueles que registraram um ou outro caso de interpolação generalizada não atestam o fenômeno em seus textos.

Outro argumento trazido em Namiuti (2008) para sustentar essa hipótese consiste no fato de que, ao compararmos os dados das pesquisas que contemplaram corpora de textos arcaicos aos dados do CTB, notamos uma diminuição das sentenças $\mathbf{C}-\mathbf{c l}-\mathbf{X}$-neg-V em relação às sentenças em que temos um $\mathbf{X}$ pré-verbal entre o complementador $(\mathbf{C})$ e $\mathbf{c l}$-neg-V $\mathbf{V}$ paralelamente à queda da interpolação generalizada nos textos produzidos entre o século XV e XVI. ${ }^{5}$

(5) "Que edeficios perpetuos e statuas pesadas tem inda esta cidade, que lhe eu $\underline{\text { uá não }}$ tenha roubado e leve, sem carretas nem navios, em leves folhas?" - Holanda, 1517.

(6) "A qual permitirá Deus, que ainda em nossos dias se descubra toda, para que com ela se aumente muito a coroa destes Reinos: aos quais desta maneira esperamos (mediante o favor divino) ver muito cedo postos em tão feliz e próspero estado, que mais se não possa desejar." - Gandavo, 1502.

(7) "Isto digo, enquanto Vossa Reverência lhe não der os ditos mil cruzados que disse." -Sousa, 1556.

Para a comparação dos dados nos diferentes corpora em um gráfico cujo eixo x é o eixo do tempo, é preciso utilizar-se das datas de produção dos textos, não há como utilizar as datas de nascimento dos autores (como é feito para o CTB), já que existe, para os textos arcaicos, uma complicação para se identificar o autor e sua data de nascimento, sendo a data do texto a única informação disponível. 


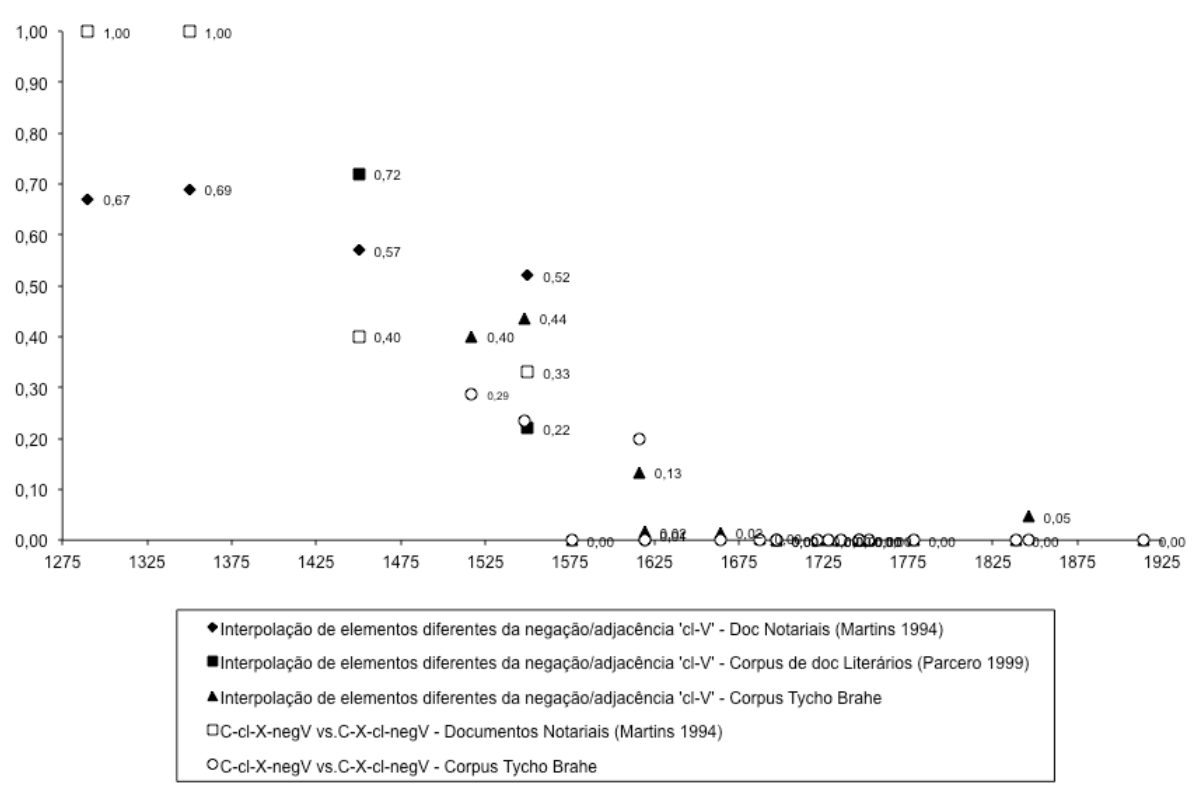

Gráfico 1 - Queda de C-cl-X-neg-V e estabilização da ordem C-X-cl-neg-V

Fonte: Autoria própria.

A ordem $\mathbf{C}$-X-cl-neg-V parece estabilizar-se nos textos produzidos a partir do século XV (Gráfico 1). Tal resultado corrobora a hipótese de que a interpolação de elementos diferentes da negação entre o clítico e o verbo está no seu estado decadente no século XV, em vias de desaparecer por completo dos textos, e já competindo com uma nova gramática. ${ }^{6}$

Quanto à interpolação da negação, ela continua a ser frequentemente atestada para muito além do século XVII, e, conforme demonstrado em Namiuti (2008), traz preciosas pistas sobre a gramática que sucede a do português antigo e sobre a mudança observável no século XVIII que originou o português europeu moderno. $^{7}$

Focalizemos os séculos XV e XVI, período contemplado nesta reflexão. Vimos, na tabela 1, que a interpolação de elementos diferentes da negação, apesar de já

\footnotetext{
No século XIX, voltamos a atestar a interpolação de sujeitos pronominais no texto de Almeida Garrett (17991854) - 5\% -, como podemos verificar no quadro 1 (Ex: "Agora, do frade é que me eu queria rir, mas não sei como." - GARRETT, 1799). O estudo de Magro (2007) mostra que a interpolação de certos elementos diferentes da negação volta a existir no português europeu moderno (PE) como um fenômeno dialetal. Porém a interpolação existente em alguns dialetos no PE moderno não é a mesma interpolação do PA (MAGRO, 2007; NAMIUTI, 2008).

7 Galves (2004), também Galves, Namiuti e Paixão de Sousa (2006) designam o período gramatical intermediário entre o português antigo e moderno de português médio, pois a existência dessa gramática abrange um período maior que o clássico
} 
não ser preferencial, é bastante atestada em alguns dos textos mais antigos do CTB. Como então interpretar o período que abrange o século XV e XVI diante da variação apresentada pelos autores? Os autores nascidos nos anos de 1435-1542 representam o Português Antigo ou o Clássico? Qual será a gramática (no sentido gerativista) desses autores? É possível identificar tal gramática pelas estruturas sintáticas registradas em seus escritos? Estarão os autores refletindo uma competição de gramáticas e diglossia em seus textos? Afinal, podemos apontar o século XV como o final de um período gramatical ou o início de um novo período?

Veremos, na próxima seção, detalhes sobre as particularidades dos textos dos autores nascidos entre os anos de 1435-1542, buscando responder a essas questões.

Argumentaremos em favor da proposta que a gramática do português clássico, revelada claramente nos textos do final do século XVI e do século XVII, já pode ser percebida nos textos de Duarte Galvão (1435-1517), Pero Magalhães de Gandavo ( 1502-??), Francisco de Holanda (1517-1584) e Diogo do Couto (1542-1606), que representam o limite inicial e final de duas gerações (segunda metade do século XV e primeira metade do século XVI).

\section{A interpolação em Duarte Galvão (1435-1517), Pero Magalhães de Gandavo (1502-??), Francisco de Holanda (1517-1584) e Diogo do Couto (1542-1606)}

Como pudemos constatar na seção anterior, o fenômeno da interpolação generalizada é claramente obsoleto nos textos dos autores nascidos a partir da segunda metade do século XVI. Entretanto, curiosa é a situação dos autores nascidos na primeira metade do século XVI e no século XV, pois alguns parecem trazer o português antigo (doravante PA) no texto cheio de interpolações. Mas, se olharmos cuidadosamente, veremos os indícios de uma nova gramática já nesses textos.

O período em que se situa o nascimento dos quatro autores focalizados aqui (segunda metade do século XV e primeira metade do século XVI) é considerado como um período de transição da língua medieval para a clássica, durante a qual coexistem formas próprias da etapa anterior com formas que já anunciam o português do período clássico (CASTRO, 1991; MAIA, 1986; BECHARA, 1991; CARDEIRA, 2005). Um período de transição deverá, portanto, caracterizar-se pela instabilidade resultante da conjugação dos sinais de renovação que se cruzam com a permanência da gramática antiga. No caso dos quatro textos aqui apresentados - de Duarte Galvão (1435-1517), Pero Magalhães de Gandavo ( 1502-??), Francisco de Holanda (1517-1584) e Diogo do Couto (1542-1606) -, 
de fato encontramos essa situação de instabilidade com relação à colocação de clíticos, mais especificamente quanto ao fenômeno da interpolação. No texto de Pero Magalhães de Gandavo não há interpolação generalizada, e encontramos um caso de interpolação da negação em uma coordenada raiz $\mathbf{e - X - V}$ (contexto de variação $\mathrm{clV} / \mathrm{Vcl}$ ).

(8) "E daí por diante se não pode passar por respeito de uma cachoeira" - GANDAVO, 1502.

Nos outros três textos, apesar da presença relevante de dados de interpolação generalizada, atestados nos mesmos contextos registrados por Martins (1994) para o PA (orações subordinadas finitas, infinitivas introduzidas por preposições que condicionavam obrigatoriamente a próclise e orações principais introduzidas por operadores proclisadores), também encontramos a negação interpolada em ambientes de variação ênclise/próclise.

$\mathrm{X}-\mathrm{cl}-\mathrm{neg}-\mathrm{V}$ :

(9) "Depois da batalha vencida efteve ElRey D.Affonfo tres dias no campo, como hee de coftume fazerem os Reys fe forçados, necefidade lhes nom vem." - Galvão, 1435 .

(10) "[...] avendo jàa fete annos que fora levantado por Rey, e fazendo finquoenta, e dous annos de fua idade, e por fe nom achar efcrito nada das coufas, que fe nefte cazamento fizeraõ, nem como foram, re nom $\mathbf{p o z}$ aqui mais, que lóomente cazar ElRey." - Galvão, 1435.

e-cl-neg-V:

(11) "Não sómente ao outro domingo seguinte não nos pudemos ajuntar com a senhora Marquesa e com Micael Angelo, mas inda ao outro, d'ali a oito dias fomos quasi empedidos e nos não queriamos congregar." - Holanda, 1517.

mas-S-cl-neg-V:

(12) "[...] e semelhantemente diz que em Lenuvio stauão pintados Atalanta e Helena despidas, da mão d'aquelle mesmo mestre, de fórma excelente, nem se danarão pola ruina do templo em que stauão; e que Pontio, legado de Caio Cesar, aceso de libide, as quis arrancar da parede, mas a natureza d'ella o não consintio, e [...." - Holanda, 1517.

A interpolação, mesmo da negação, em contextos sem operadores que condicionam categorialmente a próclise verbal não é permitida no Português Antigo, e é característica dos textos do Português Clássico. É importante ressaltar 
que a negação não conta como operador proclisador para a interpolação uma vez que ela é o elemento interpolado (MARTINS, 1994).

Nos textos de Duarte Galvão (1435-1517) e Francisco de Holanda (1527), apesar de a interpolação de elementos diferentes da negação não ser tão frequente, como nos documentos anteriores (MARTINS, 1994; PARCERO, 1999), não é marginal. Ao compararmos com as próclises com adjacência 'cl-V' o texto de Francisco de Holanda contou com 43\% de interpolação contra 57\% de cl-V, e o texto de Duarte Galvão - 40\% contra 60\%.

Já Diogo do Couto (1542-1606) apresenta apenas 15\% de interpolação de elementos diferentes da negação contra $85 \%$ de próclise com adjacência, o que, somado ao fato de Pero Magalhães de Gandavo ( 1502-??) não registrar interpolação de elementos diferentes da negação em seu texto, pode indicar que estamos diante da mudança que tornará a interpolação generalizada obsoleta ainda no século XVI.

Os contextos em que a interpolação generalizada aparece nos textos de Duarte Galvão, Francisco de Holanda e Diogo do Couto são os mesmos contextos em que a interpolação era possível nos corpora de Martins (1994) para o período anterior (orações subordinadas finitas e infinitivas introduzidas por preposição, e em orações raízes introduzidas por proclisadores). Seguem abaixo alguns exemplos.

Interpolação de advérbios, quantificadores, PPs, sujeitos e complementos fronteados em orações dependentes finitas - 'C-cl-X-V':

(13) "[...] diguaõ-no hos que le ally acharaõ, porque nom he em my dizelo." - Galvão, 1435.

(14) "Finado D.Eguas, e mandado afi enterrar como dito he, ho Princepe D.Affonfo Anriques como quer que lhe muyto pezare do falecimento de tam honrado Cavalleyro." - Galvão, 1435.

(15) "Hos de cavallo cheguando aho porto deram aguoa de feu vaguar, ElRey carreguoufe mais de fua prognoftiqua, e cheguãdo Auzary, contoulhe como le tomára ha Villa, e da grande mortindade que re nella fizera de que ElRey de Sevilha, e todos hos Mouros ouveram grande pezar, nom róo pela perda defta Villa, mas de outras ha que ha perda defta dava cauza forçada." - Galvão, 1435.

(16) "[...] e foy prezo delRey D.Fernando de Liaõ, como le aho diante diràa onde elles tiveram feu arrayal de ante fentado, no qual acharaõ prezas grandes, e ouro, e prata, e muitas joyas, e cavallos, e outras coufas, has quaes repartio por efes Grandes." - Galvão, 1435. 
(17) “[...] porque consiste toda esta arte na pintura, para saber quanto lhe a cousa diminue ao longe, e quanto ao perto crece [...]." - Holanda, 1517.

(18) “Deixo já seus vãos favores e carezas, de que me ás vezes corro." - Holanda, 1517.

(19) "Mór pergunta, todavia foi essa, (lhe respondi eu), senhor Micael, que a que vos eu preguntei."- Holanda, 1517.

(20) "como se logo fez" - Couto, 1542.

(21) "que lhe melhor parecessem" - Couto, 1542.

(22) "que o mais inquietava que todas" - Couto, 1542.

(23) "Em um extraordinário curso da natureza, que se neste tempo nota." - Couto, 1542.

(24) "e entregando-lhe aquele Rei o dia que se dele despedio" - Couto, 1542.

(25) "protesto que lhe o outro mandava fazer" - Couto, 1542.

(26) "Garcia de Sá sobre os navios, e gente, que lhe o Governador mandou dar, andou em dilações muito"- Couto, 1542.

Interpolação de sujeito em orações infinitivas introduzidas pelas preposições "de"e "sem":

(27) “E, pelo ElRei Dom João o III querer casar, e êle não querer, lhe não deram satisfação de seus serviços, que foi causa de se êle ir viver a Veneza com sua licença" - Couto, 1542.

(28) "Os Capitães Fidalgos, e todos os mais ficaram embaraçados com tão subita mudança, sem lhes o Governador dar conta do que passava ." - Couto, 1542.

(29) "sem lhe ninguém ir à mão"- Couto, 1542.

Interpolação de sujeito, complemento fronteado em orações não dependentes finitas introduzidas por operadores proclisadores.

(30) “[...] e enfadar-se-hia, e porventura se iría um dia de enfadada lançar no mar oceano, que é lá perto, e far-me-hia muitas vezes cantar aquelle verso de: Se ella servisse em o tempo da guerra, logo a eu desejaria." - Holanda, 1517.

(31) E os bons poetas a cousa por que se mais cansam e que têm por mór fineza é com palavras (porventura demasiadas e longas) vos mostrar como pintada uma tormenta do mar, ou um incendio de uma cidade, que se elles podessem, antes o pintariam; a qual tormenta quando acabaes com trabalho de lêr, já vos 
o começo esquece, e sómente tendes presente o curto verso em que levaes os olhos. - Holanda, 1517.

(32) "Mas a altura do seu rosto, da barba até o começo do nariz, é a terça parte; do começo do nariz até o fim que stá entre as sobrancelhas outro tanto; d'ali até á raiz dos cabellos, onde se o rosto acaba, é outra terça parte." - Holanda, 1517.

(33) "e onde o nós conversámos (como em outra parte dissemos)" - Couto, 1542.

Interpolação de mais de um constituinte em orações dependentes finitas ( ' $C$ - $c$ l$X-X-V$ ) e infinitivas (envolvendo sujeitos, advérbios e negação):

(34) "Como ella me mandou assentar, e se acabou a lição e os seus louvores, olhando pera mi e pera Messer Lactancio, se me eu não engano, começou a dizer: '- Logo Francisco de Hollanda tomara de mais boa vontade ouvir prégar da pintura Michael Angelo, que não frate Ambrosio esta lição' "? - Holanda, 1517.

(35) "Até aqui temos, em parte, mostrado, como em memoria, o que nos inda não esquece da nobre pintura antigua, e isto muito brevemente para o muito que poderamos fallar d'esta materia." - Holanda, 1517.

(36) "Que edeficios perpetuos e statuas pesadas tem inda esta cidade, que lhe eu já não tenha roubado e leve, sem carretas nem navios, em leves folhas?" - Holanda, 1517.

(37) "A cousa, de que me hoje mais glorio" - Couto, 1542.

(38) "que lhe EIRei depois estranhou tanto" - Couto, 1542.

(39) "e é a cousa de que se os Grandes mais honrão, que tôdas" - Couto, 1542.

(40) "porque assim determinava eu de fazer, se me Deos lá levara"- Couto, 1542.

(41) "que lhe êle não quiz dar, com bem ruins escusas" - Couto, 1542.

(42) "e que quando lhe ElRei não desse de comer, que viveria com o que seu pai viveo" -Couto, 1542.

(43) "que também lho largou, e se foi pera Cochim pera se embarcar pera o Reino, agravado de lhe ElRei não escrever, e em Cochim achou cartas suas na náo do Calataud" - Couto, 1542.

A tabela 1, considerando todas as possibilidades de interpolação de elementos diferentes da negação, apresenta, respectivamente, 40\%, 0\%, 44\% e 15\% de realização do fenômeno nos textos de Duarte Galvão, Pero M. Gandavo, Francisco de Holanda e Diogo do Couto. Para melhor avaliarmos o fenômeno 
nos textos dos autores, é interessante medirmos a frequência da interpolação de acordo com o tipo específico do elemento interpolado. A seguir, na próxima seção, descreveremos esses e outros detalhes da variação: interpolação vS próclise com adjacência clV, nos textos de Duarte Galvão e Francisco de Holanda, por ambos se comportarem de maneira semelhante com relação ao fenômeno em questão. Também descreveremos com mais detalhes o fenômeno da interpolação no texto de Diogo do Couto, já marginal, porém significativo, se comparado aos textos posteriores. Seguidamente apresentaremos os elementos finais para a conclusão.

\section{A interpolação generalizada nos textos de Duarte Galvão (1435-1517) e Francisco de Holanda (1517-1584).}

Duarte Galvão e Francisco de Holanda têm, respectivamente, 40\% e 44\% de interpolação generalizada, considerando todos os casos de próclise com adjacência 'clV' e um constituinte pré-verbal interpolável. Ao separarmos a interpolação de acordo com o elemento interpolado, considerando apenas os constituintes que de fato ocorreram interpolados em cada texto, temos as seguintes tabelas:

Tabela 2 - Interpolação generalizada de acordo com o elemento interpolado no texto de Galvão, 1435

\begin{tabular}{llllllll}
\hline Autor: G_009 & $\begin{array}{l}\text { Sujeito (nominais, } \\
\text { pronominais, } \\
\text { imprecativos, } \\
\text { demonstrativos) }\end{array}$ & Advérbios & $\begin{array}{l}\text { PP (simples, } \\
\text { adverbiais, } \\
\text { locativos e } \\
\text { OI } \\
\text { fronteados) }\end{array}$ & $\begin{array}{l}\text { QP } \\
\text { s }\end{array}$ & $\begin{array}{l}\text { Outros } \\
\text { constituintes }\end{array}$ & $\begin{array}{l}\text { mais de um } \\
\text { constituinte } \\
\text { (todos } \\
\text { diferentes de } \\
\text { negação) }\end{array}$ & TOTAL \\
\hline Interpolação & 22 & 26 & 8 & 4 & 2 & 11 & 73 \\
& 0,46 & 0,63 & 0,22 & 0,4 & 0,28 & 0,32 & 0,47 \\
\hline Adjacência & 26 & & & 4 & & 23 & 83 \\
clV & 0,54 & 15 & 29 & 5 & 5 & 0,53 \\
& & 0,37 & 0,78 & 0,5 & 0,72 & & 0,68 \\
\hline TOTAL & 48 & & & 6 & & 34 & 156 \\
\hline
\end{tabular}

Fonte: Autoria própria. 
Tabela 3 - Interpolação generalizada de acordo com o elemento interpolado no texto de F. Holanda, 1517

\begin{tabular}{|c|c|c|c|c|c|c|c|}
\hline Autor: H_001 & $\begin{array}{l}\text { Sujeito (nominais, } \\
\text { pronominais, } \\
\text { imprecativos, } \\
\text { demonstrativos) }\end{array}$ & Advérbios & $\begin{array}{l}\text { PP (simples, } \\
\text { adverbiais, } \\
\text { locativos e } \\
\text { OI } \\
\text { fronteados) }\end{array}$ & QPs & $\begin{array}{l}\text { Outros } \\
\text { constituintes }\end{array}$ & $\begin{array}{l}\text { mais de um } \\
\text { constituinte }\end{array}$ & TOTAL \\
\hline Interpolação & $\begin{array}{l}24 \\
0,57\end{array}$ & $\begin{array}{l}20 \\
0,39\end{array}$ & $\begin{array}{l}14 \\
0,58\end{array}$ & $\begin{array}{l}2 \\
0,25\end{array}$ & $\begin{array}{l}1 \\
0,11\end{array}$ & $\begin{array}{l}15 \\
0,45\end{array}$ & $\begin{array}{l}76 \\
0,45\end{array}$ \\
\hline $\begin{array}{l}\text { Adjacência } \\
\text { clV }\end{array}$ & $\begin{array}{l}18 \\
0,43\end{array}$ & $\begin{array}{l}31 \\
0,61\end{array}$ & $\begin{array}{l}10 \\
0,42\end{array}$ & $\begin{array}{l}6 \\
0,75\end{array}$ & $\begin{array}{l}8 \\
0,89\end{array}$ & $\begin{array}{l}18 \\
0,55\end{array}$ & $\begin{array}{l}91 \\
0,55\end{array}$ \\
\hline TOTAL & 42 & 51 & 24 & 8 & 9 & 33 & 167 \\
\hline
\end{tabular}

Fonte: Autoria própria.

Notamos que a diferença para o resultado anterior, apresentado na tabela 1, quanto ao total geral, é mínima na maioria dos contextos. Apesar de haver uma variação nas frequências de acordo com o constituinte interpolado, as tabelas 2 e 3 confirmam que a interpolação generalizada é bastante produtiva em ambos os textos, mesmo quando está em jogo mais de um constituinte.

A interpolação de mais de um elemento também foi atestada nos corpora de Martins (1994) e Parcero (1999) e desaparece juntamente com a interpolação de XPs no século XVII, em ambos os corpora.

Seguem abaixo alguns exemplos de construções de mais de um elemento interpolado dos dezesseis casos atestados por Parcero (1999). CL-X-neg-V, $\mathbf{C L}-\mathbf{X}-\mathbf{X}-\mathbf{V}$ e $\mathbf{C L}-\mathbf{S}-\mathbf{X}-\mathbf{V}^{8}$ são as diferentes possibilidades de interpolação de dois constituintes.

(44) "salvo a aaqueles que o gaanhar nom podem" (PARCERO, 1999, p. 49).

(45) "que sse de Castella per'eelle veherom" (PARCERO, 1999, p.49).

(46) "assim [...] como os eu d'ante avia" (PARCERO, 1999, p. 50).

A tabela 4, a seguir, revela que, dos tipos de constituintes interpolados nos textos de D. Galvão e F. de Holanda nas sentenças com mais de um constituinte, sendo todos diferentes da negação, o sujeito (S) é frequentemente um dos elementos antepostos ou interpolados.

8 CL: clítico; X: qualquer constituinte; neg: negação; S: sujeito; V: verbo 
Tabela 4 - Interpolação/adjacência 'clV' com mais de um constituinte pré-verbal diferente de negação

\begin{tabular}{|c|c|c|}
\hline Autor & G009 & H001 \\
\hline $\mathrm{C}^{9}$-cl-S-X-V & $\begin{array}{l}6 / 15(0,40) \\
6 / 34(0,17)\end{array}$ & $\begin{array}{l}4 / 7(0,57) \\
4 / 30(0,13)\end{array}$ \\
\hline C-S-X-clV & $\begin{array}{l}9 / 15(0,60) \\
9 / 34(0,26)\end{array}$ & $\begin{array}{l}3 / 7(0,43) \\
3 / 30(0,10)\end{array}$ \\
\hline Total $S-X$ & $15 / 34(0,44)$ & $7 / 30(0,23)$ \\
\hline C-cl-X-S-V & $\begin{array}{l}1 / 6 \quad(0,16) \\
1 / 34(0,03)\end{array}$ & $\begin{array}{l}2 / 5(0,40) \\
2 / 30(0,06)\end{array}$ \\
\hline C-X-S-clV & $\begin{array}{l}5 / 6(0,84) \\
5 / 34(0,15)\end{array}$ & $\begin{array}{l}3 / 5(0,60) \\
3 / 30\end{array}$ \\
\hline Total $X-S U J$ & $6 / 34(0,17)$ & $5 / 30(0,16)$ \\
\hline C-cl-X-X-V & $\begin{array}{l}4 / 13(0,31) \\
4 / 34(0,12)\end{array}$ & $\begin{array}{l}6 / 18(0,33) \\
6 / 30(0,20)\end{array}$ \\
\hline C-X-X-clV & $\begin{array}{l}9 / 13(0,69) \\
9 / 34(0,26)\end{array}$ & $\begin{array}{l}12 / 18(0,67) \\
12 / 30(0,40)\end{array}$ \\
\hline Total $X-X$ & $13 / 34(0,38)$ & $18 / 30(0,60)$ \\
\hline $\begin{array}{l}\text { TOTAL } \\
\text { DADOS }\end{array}$ & 34 & 30 \\
\hline
\end{tabular}

Fonte: Autoria própria.

Entretanto, um fator interessante a ser observado é que, no texto de Duarte Galvão (tabela 5, a interpolação de mais de um constituinte, sendo um deles o sujeito, é mais frequente quando temos o sujeito como o elemento mais externo do grupo de constituintes interpolados (S-X - 40\% de interpolação).

(47) "Quando ho Prior de Santa Cruz ha que chamavam Theotonio homem ante ElRey muito eftimado, vio tomada Leyria, que lhe ElRey D.Affonfo com muita devaçaõ, e von tade tinha dado, tomou em fy grande pezar." - Galvão, 1435.

(48) “[...] nem manteuda cõ ElRey de por meyo em fua terra, que abaftava para elles leyxarem-na em poder de Chriftãos como fora feu dezejo, e afi fe foraõ ha ElRey, e lho diceraõ muy francamente, ho que lhes elle muito agradeceo, offerecendo-fe, que fe alguns delles, e de fuas gentes quizefem fiquar em fua terra, elle lhe daria luguares." - Galvão, 1435.

(49) "ho medo, em, que os $\underline{\text { Deos }}$ jaa poz para nós ma-yormente fe dermos nelles de fobre- falto" - Galvão, 1435.

9 C: operador/subordinador. 
(50) "Entaõ ElRey movido ha devaçaõ pelas couzas que lhe feu irmão afị contava, dice" - Galvão, 1435.

(51) "E sorrindo-se Micael, dixe: - 'Porque elle sabe, senhora, que o eu já tenho feito, e lha tenho toda largado já a elle; por me não achar com as forças que pedem tamanhos amores, tem elle dito o que tem dito, como de cousa sua.' " - Holanda, 1517.

(52) “[...] e estão mui longe de o fazerem, porque a quem o a speriencia depois de muito $\underline{\text { trabalho }}$ mostrou, este sabe e sente quão deficel cousa é esta invenção de pintura de preto e branco, cuberta do rócio ou nevoa ou veos, que digo" - Holanda, 1517.

Já quando temos a ordem contrária $(X-S)$, a opção pela adjacência 'clV' é preferencial (84\% de adjacência contra 16\% de interpolação).

(53) “[...] que me fez leyxar ho modo de meu viver ordenado, e tomar vida da andar em guerra, no que me ainda Deos ajudou tanto que tomey ha Villa da Arronches [...." - Galvão, 1435.

Não se pode saber dessa forma generalizante se essa diferença é relevante, mas é curioso o fato, uma vez que se estipula que o sujeito pré-verbal poderia ocupar posições diferentes na estrutura da oração, e que este também pode ser um lugar para se investigar a mudança (a ordem SXV é a estrutura que encontramos tipicamente nos fronteamentos V2, enquanto XSV é mais tipicamente de línguas SV).

Ao medirmos a frequência de $\mathbf{S}-\mathbf{X}, \mathbf{X}-\mathbf{S}$ e $\mathbf{X X}$ dos dados de interpolação vS próclise apresentados na tabela 5 acima constatamos que o texto de Duarte Galvão apresenta a frequência de $\mathbf{0 , 4 4}$ de $\mathbf{S}-\mathbf{X}$ (ou seja, 44\%), $\mathbf{0 , 1 7}$ de $\mathbf{X}-\mathbf{S}$ (17\%) e $\mathbf{0 , 3 8}$ de $\mathbf{X}-\mathbf{X}$ (38\%); enquanto o texto de Francisco de Holanda apresenta $\mathbf{0 , 2 3}$ de $\mathbf{S}-\mathbf{X}(23 \%), \mathbf{0 , 1 6}$ de $\mathbf{X}-\mathbf{S}(16 \%)$ e $\mathbf{0 , 6 0}$ de $\mathbf{X}-\mathbf{X}(60 \%)$.

Não será possível entrar nesta questão aqui, no entanto, o sujeito parece se comportar como qualquer constituinte fronteado nas orações subordinadas.

Quanto à negação, a interpolação de 'não' é quase categórica no texto de Duarte Galvão (95\%). Porém, no texto de Francisco de Holanda, notamos uma diferença de quase $50 \%$ da interpolação do operador de negação (46\% de clneg-V) (Tabela 2). Esse fato poderia ser interpretado como uma revelação de uma diferença gramatical, porém não deverá ser esse o caso, visto que o texto de F. de Holanda destoa também de todos os outros textos com relação à preferência pela ordem $\mathbf{N e g - c l - V}$.

Consideramos que a preferência pela ordem da próclise com adjacência 'clV' nas orações dependentes negativas, neste texto, pode ser explicada pela grande 
quantidade de casos com elementos pré-verbais além da negação que parece favorecer a ordem $\mathbf{N e g - c l - V}$, apesar de não impedir a interpolação de não.

Apesar da representativa incidência de interpolação de elementos diferentes da negação, é possível encontrar, em ambos os textos, pistas da nova gramática ao observar, com mais detalhamento, as orações negativas com um elemento pré-verbal além da negação, sobretudo na questão da contiguidade entre o subordinador e o clítico: as estruturas $\mathbf{C}-\mathbf{c l}-\mathbf{X}-\mathbf{N}-\mathbf{V} \sim \mathbf{C}-\mathbf{X}-\mathbf{c l}-\mathbf{N}-\mathbf{V} \sim \mathbf{C}-\mathbf{X}-\mathbf{N}-\mathbf{c l}-\mathbf{V}$.

Tabela 5 - Interpolação vs adjacência cl-V com mais de um constituinte pré-verbal (incluindo a negação)

\begin{tabular}{lll}
\hline Autor & G009 & H001 \\
\hline C-cl-X-neg-V & 4 & 4 \\
& 0,23 & 0,11 \\
\hline C-X-neg-cl-V & 2 & 20 \\
& 0,12 & 0,54 \\
\hline C-X-cl-neg-V & 11 & 13 \\
& 0,65 & 0,35 \\
\hline TOTAL & 17 & 37 \\
\hline
\end{tabular}

Fonte: Autoria própria.

Nas sentenças com mais de um elemento pré-verbal sendo um deles a negação, a interpolação de X não ultrapassa os 23\%. Vemos, na tabela 5, que a ordem $\mathbf{C}-\mathbf{X}-\mathbf{c l}-\mathbf{N}-\mathbf{V}$ é preferencial no texto de Duarte Galvão, enquanto, no texto de Francisco de Holanda, a ordem mais atestada foi $\mathbf{C}-\mathbf{X}-\mathbf{N}-\mathbf{c l}-\mathbf{V}$, porém também com uma frequência bastante elevada de $\mathbf{C}-\mathbf{X}-\mathbf{c l}-\mathbf{N}-\mathbf{V}$. Ou seja, a ordem com interpolação do $\mathbf{X}$ pré-verbal nas orações negativas é marginal em ambos os textos. Fato que pode indicar que a mudança gramatical que veda a subida do clítico para além dos núcleos funcionais associados à morfologia verbal já foi indiciada nesta época. E pode ser constatada já no texto de Duarte Galvão (1435-1517).

A semelhança encontrada nos textos de D. Galvão (1435-1517) e F. Holanda (1517-1584) sugere que ambos compartilham da mesma gramática. Em ambos já estaria presente a gramática do português clássico ${ }^{10}$ coexistindo, em seus textos, com a gramática antiga em uma situação de competição de gramáticas. Hipótese corroborada pelo texto de Pero M. de Gandavo, que já não apresenta a interpolação de elementos diferentes da negação.

10 Galves (2004) e também Galves, Namiuti e Paixão de Sousa (2006), considerando que é o surgimento de novas formas na língua que indica a emergência de uma nova gramática, convencionaram chamar o período gramatical que abrange o século XV, XVI e XVII de Português Médio, pois abarca um período maior que o tradicional Português Clássico. 
Também o texto de Diogo do Couto revela um quadro de mudança nas sentenças não negativas. Como vimos na tabela 1, a frequência de interpolação versus próclise com adjacência $\mathbf{V}$-cl de elementos diferentes da negação no texto deste autor é bastante inferior à atestada por D. Galvão e por F. de Holanda.

A seguir veremos a situação do fenômeno da interpolação no texto de Diogo do Couto.

\section{A interpolação generalizada no texto de Diogo do Couto (1542-1606):}

Os elementos encontrados interpolados em Diogo do Couto foram: em primeiro lugar, a negação, depois os sujeitos, advérbios ${ }^{11}$ adjetivos, sintagmas preposicionais fronteados (PP), e alguns casos com mais de um constituinte entre o clítico e o verbo - sendo, geralmente: sujeito + negação, sujeito + advérbio e advérbio + advérbio.

Primeiramente, focalizaremos a frequência do fenômeno da interpolação de elementos diferentes da negação.

Ao considerarmos as possibilidades de interpolação do português antigo, o texto de Diogo do Couto possui apenas 15\% de interpolação de elementos diferentes da negação (Tabela 1).

Esse quadro muda pouco quando separamos de acordo com a especificidade dos elementos que foram interpolados no texto. Como podemos constatar na tabela 6 , a preferência continua ser a próclise sem interpolação. ${ }^{12}$

Tabela 6 - Interpolação generalizada de acordo com o elemento interpolado

\begin{tabular}{llllll}
\hline Autor: C_007 & $\begin{array}{l}\text { Sujeito } \\
\text { pronominais, } \\
\text { imprecativos, } \\
\text { demonstrativos) }\end{array}$ & (nominais, & Advérbios & $\begin{array}{l}\text { PP } \begin{array}{c}\text { (simples, } \\
\text { adverbiais, } \\
\text { locativos e }\end{array} \\
\text { fronteados) }\end{array}$ & $\begin{array}{l}\text { mais de um } \\
\text { constituinte }\end{array}$ \\
\hline Interpolação & 21 & 2 & 2 & 2 & 10 \\
& 0,21 & 0,06 & 0,04 & 0,50 & 0,32 \\
\hline Adjacência clV & 77 & 30 & 44 & 2 & 21 \\
& 0,79 & 0,94 & 0,96 & 0,50 & 0,68 \\
\hline TOTAL & 98 & 32 & 46 & 4 & 31 \\
\hline
\end{tabular}

Fonte: Autoria própria.

$11 \operatorname{Adv}(\mathrm{A})$ e Adv (a) são, respectivamente, advérbios neutros e advérbios tipo operador-atrator do clítico.

12 Há a exceção dos adjetivos (50\% de interpolação), porém, como essa categoria é rara no texto como um todo e como não é um elemento particularmente interpolado nem mesmo nos corpora de textos arcaicos (remeto aos corpora de Martins (1994) e Parcero (1999); acredito que o fato de termos dois casos de interpolação contra dois de próclise com adjetivos não é significativo). 
Quanto à interpolação de mais de um constituinte, apesar de termos a preferência pela próclise constatada na tabela 6 , ainda temos uma quantidade surpreendente de interpolação de mais de um elemento nesse texto. Resta-nos entender o porquê.

Dos vinte e um casos de próclise com dois elementos antecedendo clV apenas seis apresentaram a mesma combinação de constituintes pré-verbais distribuídos da seguinte forma:

Tabela 7 - Interpolação/adjacência com mais de um constituinte pré-verbal

\begin{tabular}{llll}
\hline Autor: C_007 & Sujeito +neg & Advérbio + Adv (A) & Sujeito + adv (a) \\
\hline Interpolação & 5 & 1 & 4 \\
& 0,56 & 0,50 & 0,80 \\
\hline Adjacência clV & 4 & 1 & 1 \\
& 0,44 & 0,50 & 0,20 \\
\hline TOTAL & 9 & 2 & 5 \\
\hline
\end{tabular}

Fonte: Autoria própria.

A tabela 7 nos traz um paradoxo. Como um texto que usa tão pouco a interpolação generalizada quando está em causa um constituinte pode preferir a estrutura com interpolação quando estão em causa dois constituintes? A esse respeito temos mais a observar:

Dos dez dados de interpolação de mais de um constituinte cinco são de Sujeito+negação, ou seja, o operador de negação sentencial é um elemento frequente nesses dados e pode nos ajudar a enxergar uma coerência maior na distribuição dos dados de interpolação.

A ordem -cl-X-neg-V é portanto produtiva neste texto (cinco casos de -cl$\mathbf{X n e g V}$ para seis de -X-neg-cl-V). Porém, ao olhar para a natureza dos elementos interpolados nas sentenças -cl-X-neg-V, constatamos que $\mathbf{X}$ é sempre o sujeito das orações. Assim, restringimos nosso conjunto de dados de próclise com adjacência $\mathbf{~} \mathbf{l V}$ para apenas -S-neg-cl-V e obtivemos cinco casos de interpolação de sujeito + negação (56\%) para quatro casos de próclise com adjacência clV antecedida de sujeito + negação (44\%).

\section{cl-S-N-V}

(56) "E temendo-se que os Castelhanos fôssem ao Moro, determinou de mandar lá uma Armada; e porque não tinha mais que duas fustas, pediu a ElRei algumas corocoras, que lhe êle não quiz dar, com bem ruins escusas, porque não quiz anojar o Rei de Geilolo [...]." - Couto, 1542. 
(57) "Isto lhe disse de todo seu ânimo; e certo que se lhe ElRei não mandára sucessor, que o houvera de fazer, porque era um Fidalgo muito determinado." - Couto, 1542.

(58) “[...] o que êle por então não quiz fazer, porque como sua tenção era haver às mãos Mealecan, ou o fazer lançar pera parte onde se êle não receasse, houve que lhe bastavam pera isso os penhores que tinha." - Couto, 1542.

(59) " [...] dizendo-lhe, que era filho mais velho de seu pai, que se queria ir pera o Reino, e que quando lhe EIRei não desse de comer, que viveria com o que seu pai viveo" - Couto, 1542.

(60) "António da Silveira, o de Terena, ia no galeão São João, que era de João de Sepulveda, que também lho largou, e se foi pera Cochim pera se embarcar pera o Reino, agravado de lhe ElRei não escrever, e em Cochim achou cartas suas na náo do Calataud, pelo que se deixou ficar." - Couto, 1542.

\section{S-N-cl-V:}

(61) "ElRei recebeo êste homem bem, e por êle lhe respondeo: 'Que sempre fôra maltradado dos Portugueses por recolher Castelhanos; mas que se fôsse êle pera aquela Ilha, porque êle não o havia de lançar fora da terra.' " - Couto, 1542.

Todavia, as sentenças negativas apresentam ainda uma terceira ordenação que é a que contém o operador de negação interpolado e o outro constituinte interpolável antecedendo a sequência cl-neg-V.

(62) “Dom Manoel lhe disse: 'Que fizesse seu ofício; mas que se o Governador o mandava prender por lhe não fazer recebimento, nem lhe entregar as chaves da fortaleza, que êle o não fizera, senão pelo pouco caso que lhe vira fazer da fortaleza d'EIRei.' " - Couto, 1542.

(63) "E sucedendo outros, a quem êles as não queriam dar, lhas tomavam por força" -Couto, 1542.

(64) "E quem nos pode também segurar, que Mealecan, depois de Rei, nos não seja peior vizinho, que êste Abrahemo, que corre com êste Estado tão pontual [...]?" - Couto, 1542.

(62) "Êste conselho houvera Dom Christovão de tomar em princípio, tanto que se ajuntou com a Rainha, e segurar-se em parte, que os inimigos o não pudessem cercar [...]." - Couto, 1542.

(63) "Disto se escusou o Villa-Lobos, o que logo soube o Rei de Geilolo, e foi visitar o Villa-Lobos a Tidore, induzindo-o a fazer guerra aos nossos, sôbre o que êle o não ouvio." - Couto, 1542).

(64) "E estava o Villa-Lobos tão mal quisto com todos, que até o Prior dos Agostinhos, seu Confessor, o não pôde sofrer, e se passou à nossa fortaleza." - Couto, 1542. 
Portanto, ao juntarmos as sentenças $\boldsymbol{C}$-S-cl-neg- $\boldsymbol{V}$ na quantificação teremos um quadro diferente. A opção em que o sujeito não é interpolado aumenta significativamente, como podemos constatar na tabela 8 (78\% contra $22 \%$ de interpolação do sujeito).

\begin{tabular}{cl} 
Tabela 8 - C-cl-S-N-V & $\sim$ C-S-N-cl-V $\sim$ C-S-cl- \\
\hline Autor: C_007 & Sujeito +neg \\
\hline C-cl-S-neg-V & 5 \\
& 0,22 \\
\hline C-S-neg-cl-V & 4 \\
& 0,17 \\
\hline C-S-cl-neg-V & 14 \\
& 0,61 \\
\hline TOTAL & 23 \\
\hline
\end{tabular}

Fonte: Autoria própria.

Agora temos um quadro semelhante ao da interpolação/adjacência 'clV' apenas tendo o sujeito como constituinte pré-verbal (Tabela 6).

Resta-nos a curiosa elevada porcentagem de interpolação de 'Sujeito+adv' e 'adv+adv'. Talvez a causalidade destas combinações possa desviar o nosso olhar sobre os dados. Voltemos a considerar estas combinações como X-X-clV, somando as outras combinações de elementos pré-verbais. Assim, temos cinco casos de interpolação contra dezoito casos de ' $\mathrm{ClV}$ ':

Tabela 9 - Interpolação/adjacência 'clV' com dois elementos pré-verbais diferentes de 'sujeito+negação'

\begin{tabular}{ll}
\hline Interpolação & 5 \\
& 0,23 \\
\hline Adjacência clV & 17 \\
& 0,77 \\
\hline TOTAL & 22 \\
\hline
\end{tabular}

Fonte: Autoria própria. 
De novo a porcentagem de interpolação fica próxima a do 'sujeito' o que pode ser explicado por termos o sujeito como um dos elementos interpolados ou interpoláveis na maioria dos dados com mais de um constituinte pré-verbal.

Com relação à interpolação da negação, o autor apresenta um quadro semelhante ao dos autores que o sucedem (nascidos na segunda metade do século XVI e século XVII) - interpolação da negação em orações não dependentes $\mathbf{X}-\mathbf{V}$ e alto índice de não contiguidade entre complementizador e clítico nos casos de interpolação da negação em orações subordinadas.

\section{Últimas pistas e elementos para a conclusão}

Um leque bastante grande de elementos ainda pode ser interpolado até Diogo do Couto, porém parece haver aí uma restrição de peso que se acentua nos textos tardios (autores dos finais do século XVI e início do século XVII) que apresentaram casos de interpolação generalizada. Os constituintes normalmente não são muito longos, e, quando mais de um constituinte é interpolado, ao menos um deles é a negação ou um advérbio curto, ou ainda o sujeito curto (geralmente pronominal). Tal restrição não se encontra nos textos arcaicos.

Localizamos outras pistas que podem refletir uma situação de mudança gramatical e competição de duas gramáticas nesses textos mais antigos do CTB.

Os enunciados subordinados do PA, além da próclise constante, são caracterizados pela contiguidade do pronome complemento ao elemento subordinante. Essa seria a razão para a preferência à interpolação no PA (MATOS E SILVA, 1989). Quando ocorrem outros elementos, em geral, eles se intercalam entre o pronome e o verbo a fim de manter a contiguidade do operador com o clítico.

No entanto, nos textos de Galvão e Holanda, encontramos o fenômeno da interpolação generalizada sem a contiguidade entre o subordinante e o clítico, ou seja, C-X-cl-X-V (três casos nos setenta e três dados de interpolação generalizada no primeiro texto, ou seja, menos de meio por cento, $0,4 \%$, e quatro casos em setenta e seis dados no segundo, $0,5 \%$ ).

(68) "DEfque D.Eguas Moniz fe a/i partio delRey de Caftella quite, e livre de fua menagem, e com fua graça veyo caminho de Guimarães, e [...]." - Galvão, 1435.

(69) "Como quer que hos Mouros, le muy bem defendefem" - Galvão, 1435.

(70) "[...] e Deos que fempre ho ajudava em todos hos feus feytos, lhe deu tam boa efquença, que por força ha tornou ha tomar, polto que hos Mouros há muy bem defendeffem." - Galvão, 1435. 
(71) "Sómente as obras que se fazem em Italia podemos chamar quasi verdadeira pintura, e por isso a boa chamamos italiana, que, quando noutra terra se assim fezesse, d'aquella terra ou provincia lhe dariamos o nome." - Holanda, 1517.

(72) “Confesso, dixe eu, senhora, que m'a tem largado, mas ella não se quer ir comigo, de maneira que lhe torna a ficar em casa: nem eu, inda que tanto valesse, não a quereria vêr em minha patria inda agora, porque, como poucos a lá sabem stimar, e o meu serenissimo rei [...]." - Holanda, 1517.

(73) “[...] porque se costuma ás vezes pintar, como se vê em muitas partes d'essa cidade, mil monstros e alimarias, d'ellas com rostro de molheres e com pernas e com rabos de peixes, e outras com braços de tigres e azas, outras com rostos de homens, pintando finalmente aquilo de que se mais deleita o pintor e que nunca se no mundo viu"? - Holanda, 1517.

(74) "E assi como do que stava quedo fezerão prematica que nunca o mais movessem, assi a fezerão do que se movia ou andava, ou corria, ou pelejava [...]." - Holanda, 1517.

No corpus de Martins (1994), na quase totalidade dos casos de interpolação, o clítico é imediatamente adjacente ao elemento que introduz a oração e que condiciona a próclise, quer se trate de uma conjunção subordinativa ou de um pronome relativo (em orações subordinadas finitas) ou de uma preposição (em orações infinitivas). No entanto, de acordo com a autora, o clítico pode ocorrer separado quer do verbo quer do elemento que determina a próclise, indicando que a contiguidade entre o operador e o clítico não é obrigatória, podendo ocorrer um sintagma nominal (sujeito ou objeto), preposicional ou adverbial. Isso, porém, acontece raramente e somente em orações subordinadas finitas. Dos trezentos e nove casos de interpolação generalizada de Martins (1994) apenas doze apresentaram elementos entre o clítico e o complementador (ou seja, 4\%), o que mostra a preferência à contiguidade entre subordinante e clítico nos dados que representam o português antigo (documentos notariais). Dos dados de não contiguidade levantados por Martins (1994) metade são tardios (séculos XV e XVI) e, dos seis casos mais antigos (séculos XIII e XIV) cinco repetem a mesma estrutura: sse pela u $\sim$ entura.

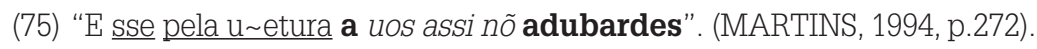

Desse fato, podemos supor que a não contiguidade $\mathbf{C - c l}$ nas estruturas com interpolação generalizada pode refletir uma instabilidade do sistema já no século XV, e os casos de não contiguidade em sentenças com interpolação generalizada nos textos de Duarte Galvão e Francisco de Holanda entrariam nesse quadro. 
A questão da contiguidade $\mathbf{C}$-cl é importante, pois as ordens $\mathbf{C}-\mathbf{c l}-\mathbf{X}-\mathbf{V}$ e $\mathbf{C}-\mathbf{X}$ $\mathbf{c l}-\mathbf{V}$ podem ser reveladoras da estrutura gramatical. A ordem $\mathbf{C}-\mathbf{c l}-\mathbf{X}-\mathbf{V}$ pode ser derivada pela possibilidade do pronome clítico se hospedar em um núcleo acima das projeções do verbo; já a ordem $\mathbf{C}-\mathbf{X}$-cl-V $\mathbf{V}$ pode ser derivada com clítico e verbo formando um complexo. Interpretamos que os casos de $\mathbf{C}-\mathbf{X}-\mathbf{c l}-\mathbf{X}-\mathbf{V}$, registrados nos textos de Duarte Galvão e Francisco de Holanda, têm o verbo em I , e o clítico no núcleo intermediário entre CP e IP, o qual, seguindo a proposta de Martins (1994) para a estrutura da sentença, chamamos de $\Sigma^{\circ}$. Acreditamos que, no português antigo, $\Sigma^{\circ}$ e $I^{\circ}$, além de $C^{\circ}$, são núcleos para onde o verbo pode se mover e onde o clítico pode se fixar, a depender das circunstâncias sintáticas (de acordo com a natureza sintática da oração), do contrário não encontraríamos variação. Tais núcleos teriam traços comuns que poderiam em alguns momentos competir na questão do movimento e checagem dos traços ( $I^{\circ}$ teria traços verbais para serem checados em $\Sigma^{\circ}$, que por sua vez teria traços a checar em $\mathrm{C}^{\circ}$ ). De acordo com a hipótese delineada em Namiuti (2008), nas sentenças subordinadas, esperaríamos apenas duas opções de derivação na posição do clítico: 1) a interpolação - com o movimento de $\Sigma^{\circ}$ para $\mathrm{C}^{\circ}$ para a checagem de traços carregando o pronome e deixando o verbo $\mathrm{em} \mathrm{I}^{\circ}$-; 2) a adjacência clV - ocasionada pela ausência do movimento de $\Sigma^{\circ}$ para $\mathrm{C}^{\circ}$ decorrente da subida do verbo para $\Sigma^{\circ}$ nas orações raízes neutras.

Assim as sentenças com interpolação de elementos diferentes da negação e sem contiguidade C-cl poderiam ser "lapsos" produzidos pela competição na checagem de traços que, por sua vez, poderiam refletir um estado de diglossia e competição de gramáticas (na gramática média, que segue o português antigo e precede o português moderno, o clítico não sobe para além de $\Sigma^{\circ}$ ).

Outro dado marginal, mas interessante, encontramos no texto de Diogo do Couto: uma sentença com duplicação do clítico - o pronome se encontra antes e depois do constituinte pré-verbal. Tal dado foi desconsiderado por apresentar adjacência 'cl-V' e interpolação simultaneamente.

(76) "E em quanto se estas se negoceão, e solicitão" - Couto, 1542.

Essa construção, somada aos casos de interpolação sem contiguidade entre o subordinador e o clítico - C-X-cl-X-V -, de Duarte Galvão e Francisco de Holanda, poderia constituir mais uma pista da existência de competição de gramáticas nos textos dessa fase. 


\section{Conclusão}

Os fatos apresentados aqui corroboram a hipótese de que a interpolação presente nos textos de Galvão (1435-1517), Gandavo ( 1502-??), Holanda (15171584) e Couto (1542-1606) refletem um estado de competição de gramáticas. Os textos dos quatro autores aqui contemplados já instanciam as formas do português clássico como a possibilidade de interpolar a negação nas orações raízes $\mathbf{X}-\mathbf{V}$ e a preferência pela ordem $\mathbf{C}-\mathbf{X}$-cl-neg-V convivendo, nos textos de Galvão Holanda e Couto, com a ordem da interpolação generalizada, bastante produtivas nos textos do século XIII e XIV (português antigo). O texto de Couto (15421606), que é o mais tardio dos quatro avaliados, apresenta um comportamento semelhante ao de Galvão e Holanda em relação ao registro de interpolação da negação em novos contextos, produtividade da interpolação da negação e da ordem $\mathbf{C}-\mathbf{X}$-cl-neg-V, juntamente com o registro de interpolação generalizada, porém essa menos frequente que nos textos dos dois autores mais antigos. $\mathrm{E}$, vindo comprovar o surgimento de uma nova ordem, uma nova gramática, neste período Pero Magalhães de Gandavo, autor nascido por volta de 1502 (ou seja, entre Galvão e Holanda), não registra um só caso de interpolação generalizada em seu texto. Apesar dos textos de seus contemporâneos atestarem uma percentagem significativa de interpolação generalizada - própria da gramática do português antigo, no texto de Gandavo, a interpolação é restrita à negação, e o fenômeno abrange as orações raízes $\mathbf{X}-\mathbf{V}$, apresentando, assim, um comportamento semelhante ao dos autores nascidos na segunda metade do século XVI e século XVII.

\section{Agradecimentos}

Agradecemos à Fundação de Amparo à Pesquisa do Estado de São Paulo (FAPESP) pelo financiamento da pesquisa que propiciou o levantamento de dados e a reflexão trazidos aqui; à UNICAMP por oferecer as condições físicas e intelectuais para sua realização, à UESB pelo recente acolhimento e ao CNPq pelo recente apoio (CNPq 401594/2010-6).

NAMIUTI-TEMPONI, C. Diglossia in times of change? The Case of interpolation in Duarte Galvão, Pero Magalhães de Gandavo, Francisco de Holanda e Diogo do Couto. Alfa, Araraquara, v.55, n.2, p.545-572, 2011.

- ABSTRACT: AcCording to Castro (1991) and Cardeira (2005), the $15^{\text {th }}$ and the early $16^{\text {th }}$ centuries are considered a transition period from the medieval language to the classic language in which forms from the old language coexist with forms that foresee the Portuguese of the classical language. Based on Castro (1991) and Cardeira (2005), and also on the notion of "grammars 
in competition" (KROCH, 1994), we argue that a transition period should be characterized by the instability resulted from the combination of the new grammar signs that intersected with the old grammar forms. In this paper, we shall present some evidences from the clitic syntax in old texts written by authors born between the $15^{\text {th }}$ and $16^{\text {th }}$ centuries; evidences that may confirm the hypothesis of grammatical instability and grammars in competition during this period.

- KEYWORDS: Syntax. Interpolation. Syntactic change. Diachrony. Generative Grammar.

\section{REFERÊNCIAS}

BECHARA, E. As fases da língua portuguesa escrita. In: KREMER, D. (Ed.). Actes du XVIII Congrès International de Linguistique et de Philologie Romanes. Tübingen: Max Niemeyer, 1991. v.3. p.68-75.

CASTRO, I. Curso de história da língua portuguesa. Lisboa: Universidade Aberta de Lisboa, 1991.

CARDEIRA, E. Entre o português antigo e o português clássico. Lisboa: Imprensa Nacional, 2005.

CORPUS Histórico do Português Tycho Brahe. Disponivel em: <http://www.tycho. iel.unicamp.br/ tycho/corpus/index.html>Acesso em: 10 jan. 2007.

FIÉIS, M. A. J. Interpolação em português medieval como adjunção a XP. In: ENCONTRO NACIONAL DA ASSOCIAÇÃO PORTUGUESA DE LINGUÍSTICA, 16., 2001, Lisboa. Actas... Lisboa: APL, 2001. p.197-211.

GALVES, C. Padrões rítmicos, fixação de parâmetros e mudança linguística-fase II. 2004. 22f. Projeto de pesquisa encaminhado a FAPESP.

GALVES, C.; NAMIUTI, C.; PAIXÃO DE SOUSA M. C. Novas perspectivas para antigas questões: revisitando a periodização da língua portuguesa. In: ENDRUSCHAT, A.; KEMMLER, R.; SCHÄFER-PRIEB, B. (Org.). Grammatische structuren des Europäischen Portugiesisch. Turbigen: Calapinus, 2006. p.45-75.

KROCH, A. Syntactic change. In: BALTIN, M.; COLLINS, C. (Ed.). The handbook of contemporary syntactic theory. Oxford: Blackwell, 2001. p.699-279.

Morphosyntactic variation. In: ANNUAL MEETING OF THE CHICAGO LINGUISTIC SOCIETY, 30., 1994, Chicago. Proceedings... Chicago: CLS, 1994. v.2. p.180-201.

. Reflexes of grammar in patterns of language change. Language Variation and Change, Cambridge, v.1, p.199-24, 1989.

LABOV,W. On the mechanism of linguistic change. Georgetown monographs on languages and linguistics, Washington D.C., n.18, p.91-114, 1965. 
MAGRO, C. Clíticos: variações sobre o tema. 2007. 275f. Tese (Doutorado em Linguística) - Faculdade de Letras, Universidade de Lisboa, Lisboa, 2007.

MAIA, C. A. História do Galego-Português. Estado linguístico da Galiza e do Noroeste de Portugal desde o século XIII ao século XVI (com referência à situação do galego moderno). Coimbra: Instituto Nacional de Investigação Científica, 1986.

MARTINS, A. M. Clíticos na história do português. 1994. 628f. Tese (Doutorado em Linguística) - Faculdade de Letras, Universidade de Lisboa, Lisboa, 1994.

MATTOS E SILVA, R. V. Estruturas trecentistas: elementos para uma gramática do português arcaico. Lisboa: Imprensa Nacional Casa da Moeda, 1989.

MEILLET A. La méthode comparative en linguistique historique. Paris: Champion, 1928.

NAMIUTI, C. Aspectos da história gramatical do português: interpolação negação e mudança. 2008. 309f. Tese (Doutorado em Linguística) - Instituto de Estudos da Linguagem, Universidade Estadual de Campinas, Campinas, 2008.

. Um estudo sobre o fenômeno da interpolação de constituintes na história do português. Caderno de Estudos Linguísticos, Campinas, v.48, n.2, p.171-194, 2006.

PARCERO, L. Fronteamentos de constituintes no português dos séculos XV, XVI e XVII. 1999. 114f. Dissertação (Mestrado em Letras e Linguística) - Instituto de Letras, Universidade Federal da Bahia, Salvador, 1999.

RIBEIRO, I. A sintaxe da ordem do português arcaico: o efeito V2. 1995. 286f. Tese (Doutorado em Linguística) - Instituto de Estudos da Linguagem, Universidade Estadual de Campinas, Campinas, 1995.

RIVERO, M. L. Subida de los clíticos y de SN em español antiguo. In: SORIANO FERNANDÉZ, O. (Ed.). Los pronomes átonos. Madrid:Taurus, 1993. p.101-136.

TEYSSIER, P. História da língua portuguesa. Tradução de Celso Cunha. São Paulo: Martins Fontes, 2001.

WEINREICH, U. Languages in contact. New York: Publications of the Linguistic Circle of New York, 1953.

Recebido em julho de 2010.

Aprovado em dezembro de 2010. 